\title{
PENTINGNYA SOSIAL MEDIA SEBAGAI STRATEGI MARKETING START-UP DI INDONESIA
}

\author{
Jessie Elita Tarihoran ${ }^{1}$, Muarifah Ika Mardiani ${ }^{2}$, Novelia Dwi Putri ${ }^{3}$, Rista Sari \\ Novareila ${ }^{4}$, Alfira Sofia ${ }^{5}$, Ida Farida Adi prawira ${ }^{6}$ \\ ${ }^{6}$ Program Studi Akuntansi, Fakultas Pendidikan Ekonomi dan Bisnis, Universitas Pendidikan \\ Indonesia ${ }^{1,2,3,4,5}$ \\ jessieelita@upi.edu, ifahika@upi.edu,noveliadwi24@upi.edu, ristasari@upi.edu, \\ alfira.sofia@upi.edu,ida.farida@upi.edu
}

\begin{abstract}
ABSTRAK
Pentingnya Sosial Media Sebagai Strategi Marketing Start-Up di Indonesia merupakan suatu hal yang harus diperhatikan, khususnya bagi para pembisnis di era industri 4.0 sekarang ini. Sosial Media sangat berpengaruh pada kegiatan marketing di zaman ini, dimana dengan menggunakan sosial media, bisnis yang kita pasarkan bisa menjadi terkenal dan menjadi perusahaan Start-Up.

Strategi marketing dengan menggunakan sosial media pun menjadi salah satu alternatif yang sangat dianjurkan, khususnya pada era industri 4.0 dan masa pandemik seperti ini. Artikel ini disusun dengan menggunakan tipe penelitian kepustakaan (library research) atau kualitatif deskriptif kepustakaan. Penelitian dilakukan dengan mengumpulkan data kualitatif dari data-data yang tersedia, seperti mengikhtisarkan poin-poin penting dari beberapa jurnal atau artikel yang telah ada lalu menarik kesimpulan berdasarkan pemikiran yang logis dan analisis.

Literatur yang digunakan penulis yaitu jurnal atau artikel ilmiah, baik yang lokal maupun internasional.
\end{abstract}

Kata Kunci : sosial media, start-up, strategi marketing, era industri 4.0.

\section{ABSTRACT}

The importance of social media as a start-up marketing strategy in Indonesia is something that must be considered, especially for business people in the current industrial era 4.0. Social Media is very influential in marketing activities today, where by using social media, the businesses that we market can become famous and become a Start-Up company.

A marketing strategy using social media is also a highly recommended alternative, especially in the industrial era 4.0 and during a pandemic like this. This article is prepared using the type of library research (library research) or qualitative descriptive literature. The research was conducted by collecting qualitative data from available data, such as summarizing the important points of several existing journals or articles and then drawing conclusions based on logical thinking and analysis.

The literature used by the author is a journal or scientific article, both local and international.

Keywords: social media, start-ups, marketing strategy, industrial era 4.0

\section{PENDAHULUAN}

Pada era industri 4.0 ini, perkembangan digital semakin pesat sehingga memberikan dampak terhadap perekonomian Indonesia yaitu meningkatnya jumlah usaha di sektor ekonomi digital salah satunya perusahaan start up di Indonesia. Menurut startupranking.com, Indonesia berada di peringkat 5 dengan jumlah startup terbanyak di dunia, di bawah United States, India, United Kingdom, Canada. Pada tahun 2021 tercatat terdapat 2.229 start-up di Indonesia. 
Berdasarkan hasil laporan Digital Creative Industry Society pada tahun 2018 jumlah perusahaan rintisan teknologi di Indonesia mencapai 992 start-up. Bidang usaha startup di dominasi oleh bidang lainnya dengan 532 startup sebesar 53,63\%. Kemudian, bidang ecommerce dengan 352 startup atau sebesar 35,38\%. Ketiga, bidang game dengan 55 startup sebesar 5,54\%. Terakhir, bidang fintech dengan 53 startup sebesar 5,34\%.

Untuk mengembangkan bisnis start-up ini, perusahaan akan melakukan berbagai strategi agar perusahaan start-up tersebut bisa menjadi perusahaan yang besar dan terkenal. Salah satu strategi yang dilakukan oleh perusahaan start-up yaitu strategi marketing perusahaan. Strategi marketing adalah elemen penting dalam sistem manajemen perusahaan, mengetahui persaingan dengan perusahaan lain dipasaran, meningkatkan pelanggan, mengetahui kelemahan dan kekuatan baru yang mempengaruhi perusahaan (Kanishchenko \& Kuznetsova, 2020). Dengan perkembangan era industri 4.0 ini dengan memanfaatkan teknologi digital memudahkan perusahaan dalam melakukan pemasaran yang biasa dikenal dengan digital marketing. Sehingga untuk melakukan strategi marketing di era digital ini perusahaan memanfaatkannya dengan melakukan pemasaran melalui media sosial. Dari data yang dikeluarkan oleh We Are Social dan Hootsuite pada Januari 2021 pengguna internet di seluruh dunia sebanyak 4,66 miliar orang, meningkat sebanyak 316 juta $(7,3 \%)$ dari tahun lalu. Dari pengguna internet tersebut sebanyak 4,20 miliar pengguna media sosial di seluruh dunia. Angka ini telah meningkat sebesar 490 juta selama 12 bulan terakhir, memberikan peningkatan dari tahun ke tahun lebih dari 13 persen. Jumlah pengguna media sosial kini setara dengan lebih dari 53 persen dari total populasi dunia. Hal ini memberikan kepada perusahaan start-up untuk melakukan promosi sehingga produk atau layanan yang dijual dapat dikenal dan menarik konsumen dari pengguna sosial media.

Media sosial marketing ini adalah alat yang penting bagi perusahaan baru, yang mana dapat membantu perusahaan pemula karena mudah digunakan dan biaya yang relatif rendah. Dengan memanfaatkan media sosial, orang-orang dari seluruh dunia dapat memberikan pendapat mereka dan menyebarkan informasi-informasi. Media sosial telah menjadi platform komunikasi yang tak terhindarkan, dan perusahaan harus menyesuaikan konsepnya dengan bisnis mereka untuk melakukan pemasaran perusahaan sebagai media promosi (Jung \& Jeong, 2020).

Dengan ini perusahaan dapat memprediksi tingkat keterlibatan media sosial perusahaan start-up yang memungkinkan untuk mengukur efektivitas upaya pemasaran media sosial dan dapat memberikan banyak manfaat yang terkait dengan pemasaran yang strategis. Melihat begitu berpengaruhnya media sosial saat ini bagi industri start up, berdasarkan hal tersebut pada penelitian ini akan dibahas mengenai pentingnya media sosial sebagai strategi marketing perusahaan startup indonesia. Adapun tujuan dari penulisan ini adalah untuk mengetahui seberapa pengaruhnya media sosial berdampak terhadap pemasaran suatu perusahaan start-up.

\section{KAJIAN LITERATUR Media Sosial}

Menurut Richter dan Koch, 2007 (dalam Situmorang et al., 2018) menyatakan media sosial merupakan sebuah fasilitas internet, aplikasi online, serta media yang diperuntukan buat memfasilitasi interaksi, kerja sama serta berbagi informasi-informasi. Dengan banyaknya media sosial ini menjadikan media sosial sebagai digital marketing perusahaan untuk lebih mudah mengenalkan produknya kepada penggunanya.

Media sosial sebagai strategi marketing perusahaan start-up adalah pemanfaatan teknologi media, perangkat lunak untuk berkomunikasi, menyampaikan pendapat, dan fasilitas untuk bertukar penawaran yang memiliki nilai untuk pemangku kepentingan organisasi (Tuten, T. L., 2020). 
Menurut Jung \& Jeong (2020), terdapat beberapa cara media sosial sebagai strategi marketing yang dapat menguntungkan perusahaan start-up: (1) Media sosial memungkinkan perusahaan start-up untuk mengkomunikasikan langsung kepada konsumen dan pemangku kepentingan, dan (2) Media sosial dapat meningkatkan pembiayaan usaha untuk perusahaan baru karena biaya yang lebih rendah, dan banyak manfaat lainnya yang dapat meningkatkan keunggulan kompetitif perusahaan baru.

Terdapat berbagai media sosial yang telah digunakan oleh pengguna internet seperti Instagram, Facebook, Twitter, Whatsapp, Youtube, Twitter, Linkedin, Tiktok, Blog, dll. Berbagai jenis media tersebut bisa dimanfaatkan perusahaan start-up untuk mempromosikan produk atau jasa yang dijualnya sehingga banyak pengguna media sosial akan mengetahui produk tersebut bahkan berpeluang untuk membelinya bahkan dengan media sosial membantu perusahaan yang baru merintis mengeluarkan biaya yg rendah untuk marketing serta tidak memerlukan waktu yang lama dalam menyampaikan produk kepada calon konsumen.

Berikut ini terdapat tiga fungsi umum penggunaan data media sosial untuk strategi marketing menurut Boerman dkk., 2017, Liu dkk., 2017, Malthouse dan Li, 2017, Sheng dkk., 2018 (dalam Jacobson et al., 2020) : (1) Memberikan pengetahuan melalui penggalian opini, (2) Menyampaikan informasi melalui iklan yang ditargetkan, dan (3) Berkomunikasi dengan pelanggan baik pelanggan baru maupun yang sudah ada.

\section{Strategi Pemasaran}

\section{Pengertian Strategi Pemasaran}

Pengertian strategi pemasaran menurut beberapa ahli diantaranya yaitu menurut Kurtz (2008), pengertian strategi pemasaran adalah keseluruhan program perusahaan dalam menentukan target pasar dan memuaskan konsumen dengan membangun kombinasi elemen dari marketing mix; produk, distribusi, promosi, dan harga.

Kemudian menurut Kotler dan Amstrong (2008), pengertian strategi pemasaran adalah logika pemasaran dimana unit bisnis berharap untuk menciptakan nilai dan memperoleh keuntungan dari hubungannya dengan konsumen.

Dan terakhir menurut Philip Kotler, pengertian strategi pemasaran adalah suatu mindset pemasaran yang akan digunakan untuk mencapai tujuan pemasaran, dimana di dalamnya terdapat strategi rinci mengenai pasar sasaran, penetapan posisi, bauran pemasaran, dan budget untuk pemasaran. Kotler menyebutkan konsep bauran pemasaran terdiri dari $4 \mathrm{P}$, yaitu: product, price, place, dan promotion.

\section{Tujuan Strategi Pemasaran antara lain :}

a. Tim pemasaran bisa meningkatkan kualitas koordinasi

b. Mengukur hasil pemasaran berdasarkan standard yang berlaku

c. Dalam setiap mengambil keputusan dapat memberikan dasar strategi yang masuk akal

d. Meningkatkan kemampuan dalam beradaptasi apabila terjadi perubahan dalam pemasaran

\section{Start-Up}

Dilansir dari situs winstarlink.com, istilah startup berasal dari bahasa Inggris yang berarti "The act or process of starting a process or machine; a new organization or business venture" atau "Suatu tindakan memulai sebuah proses, sebuah organisasi baru atau usaha bisnis". Pengertian startup menurut ahli, Paul Graham berdasarkan situsnya menyebutkan bahwa startup adalah perusahaan yang dirancang untuk tumbuh dan berkembang dengan cepat.

Startup merupakan perusahaan baru yang sedang dikembangkan atau belum lama beroperasi dengan memanfaatkan media digital untuk mendapatkan pendapatan. Untuk mempermudah menemukan makna dari star-up berikut karakteristik sebuah perusahan yang bisa dikatakan dengan perusahaan star-up yang dilansir oleh cohive.space antara lain : 
a. Memiliki mobile application untuk mendukung kegiatan bisnisnya

b. Memiliki ide atau gagasan yang inovatif \& disruptiv

c. Sumber daya manusia multitasking

d. Umumnya bergerak di bidang teknologi

e. Website menjadi sarana utama sebagai media

\section{Faktor-faktor Keberhasilan Start Up}

Berikut ini faktor-faktor penentu kesuksesan start up yang diidentifikasi oleh Prasetiawan dan Tricahyono (2017), yaitu: product, process, managerial innovation, communication, experience, information technology, innovation skills, functional skills.

a. Product

Dalam sebuah produk digital, desain merupakan sesuatu yang sangat penting dimana mampu membantu perusahaan dalam mencapai tujuan bisnisnya. Produk harus dapat diakses digunakan dengan mudah oleh semua orang sesuai dengan kebutuhan prioritasnya dan tidak membuat Pengguna dibebani dengan elemen pengganggu lainnya, sehingga pengguna merasakan kemudahan dan kenyamanan dalam menggunakan produk tersebut.

Variabel produk mencakup beberapa faktor diantaranya:

1) Kemudahan Pemakaian Produk Digital( User Experience)

2) Kemudahan berhubungan dengan Produk Digital( User Interface))

3) Estetika produk dalam Desain Produk serta Layanan Digital

4) Produk serta Layanan Digital sudah dibuat untuk membagikan pengalaman untuk pengguna

b. Process

Setelah produk digital dikembangkan, maka variabel proses fokus pada bagaimana start up menjalankan proses-proses pengembangan produk dari konsep sampai ke pelanggan sehingga memberikan solusi yang dibutuhkan oleh pelanggan (Prasetiawan \& Tricahyono, 2017). Beberapa komponen yang terkait dengan variabel proses menurut Nylén \& Holmström, 2015 (dalam Hardiansyah \& Tricahyono, 2019) adalah: (1) bundling yaitu bagaimana menggabungkan komponen portofolio produk dan layanan digital sehingga dapat didiferensisasi dan memberikan perbedaan yang jelas tentang batasan dan hubungan antar produk dan layanan; (2) devices yaitu terkait dengan informasi tentang perangkat keras dan perangkat lunak; dan (3) channel, terkait dengan digital information channel (misalnya, platform perangkat lunak, sistem operasi, dan web services).

c. Management of Innovation

Variabel manajemen inovasi adalah bagaimana start up dapat mengelola inovasi sehingga dapat menjalankan proses pengembangan produknya dengan cepat, sekaligus mengurangi ketidakpastian yang akan terjadi yang merupakan ciri khas dari produk digital (Prasetiawan \& Tricahyono, 2017).

d. Communication

Variabel komunikasi adalah bagaimana perusahaan Startup mampu mempublikasikan atau memperkenalkan perusahaan terutama nilai produk yang ditawarkan kepada pengguna sehingga dapat mempercepat penerimaan produk di pasar. Dengan demikian, dalam penelitian ini, variabel komunikasi adalah tentang bagaimana start up menginformasikan nilai produk dan standar layanan industri agar secara cepat dapat diterima oleh industri, pasar dan calon konsumen.

e. Experience

Variabel experience atau pengalaman didefinisikan sebagai pengalaman dalam proyek sebelumnya yang memungkinkan perusahaan untuk membentuk kemampuan untuk memperbaiki inovasi selanjutnya. Perusahaan harus terlibat dalam proyek-proyek yang 
membentuk pengalaman khusus untuk mengembangkan keterampilan-keterampilan teknologi, produksi dan pemasaran. (Prasetiawan \& Tricahyono, 2017).

f. Information technology

Variabel teknologi informasi adalah bagaimana start up bisa memanfaatkan teknologi informasi untuk mendukung keberhasilan bisnisnya baik sebagai produk utama atau sebagai penunjang.

g. Innovation Skills

Variabel innovation skills adalah kemampuan dasar yang mendukung keberhasilan dalam menumbuhkan bisnis digital pada pasar yang masih baru terbentuk dan dengan kondisi internal tim yang masih memiliki keterbatasan.

h. Funcitional skills

Keterampilan fungsional adalah terkait dengan bagaimana start up memiliki kemampuan dalam penggunanan teknologi informasi dan digital.

\section{METODE PENELITIAN}

Dalam menyusun artikel ini, penelitian yang digunakan penulis adalah tipe penelitian kepustakaan (library research) atau kualitatif deskriptif kepustakaan, yaitu penelitian yang dilakukan hanya mengandalkan data-data yan bersifat teoritis dan dokumentasi dalam karya tertulis, baik hasil penelitian yang telah dipublikasikan maupun yang belum. Penelitian dilakukan dengan mengumpulkan data kualitatif dari data-data yang tersedia, seperti mengikhtisarkan poin-poin penting dari beberapa jurnal atau artikel yang telah ada lalu menarik kesimpulan berdasarkan pemikiran yang logis dan analisis. Literatur yang digunakan penulis yaitu jurnal atau artikel ilmiah, baik yang lokal maupun internasional. Dari sumber pustaka tersebut peneliti mengkaji perolehan data sekunder dalam jurnal atau artikel ilmiah yang bersumber dari pihak lain. Data sekunder yang digunakan penulis berupa tulisan-tulisan, lalu penulis mengkaji dan mencoba mengulas beberapa pemikiran tentang pentingnya media sosial sebagai strategi marketing bagi start up di Indonesia serta beberapa sumber pustaka lain yang terkait dengan penelitian yang dilakukan. Penelusuran data dimulai dengan penulisan keyword "Social Media Startup" di Google Scolar dan ditemukan 115.000 artikel yang relevan. Selanjutnya pencarian artikel dipersempit dengan keyword jurnal internasional sehingga menghasilkan 71.900 artikel. Setelah itu, kami membatasi artikel yang kami cari dengan menelusuri tahun terbit jurnal antara tahun 2010 sampai tahun 2021 sehingga didapatkan 18.700 artikel terkait. Setelah itu, didapatkan beberapa artikel dan diuji pada laman Scopus.

\section{HASIL DAN PEMBAHASAN}

Sosial media marketing adalah salah satu bentuk strategi pemasaran melalui digital. Dimana para pelaku usaha menggunakan media sosial maupun website untuk mempromosikan usaha, produk atau jasa yang dimilikinya. Strategi seperti ini sangat berperan bagi kemajuan bisnis karena strategi pemasaran semakin berkembang dan terus mengikuti tren kemajuan teknologi. Di era sekarang, sudah jarang para pelaku usaha menggunakan sistem dan media pemasaran yang konvensional karena sekarang semua serba menggunakan internet agar segalanya lebih efisien. Dengan demikian, pemasaran melalui media sosial menjadi salah satu inovasi dan terobosan bagi para pelaku usaha dalam mempromosikan bisnisnya secara efisien dalam waktu, yaitu tidak harus bertemu secara langsung dengan konsumen untuk promosi dan juga efisiensi dalam biaya promosi, karena tidak perlu mengeluarkan biaya yang besar. Selain itu, kelebihan lain yang dimiliki strategi sosial media marketing yaitu memiliki jangkauan yang lebih luas serta yang paling penting adalah bersifat 'kekinian'.

Salah satu usaha yang sangat mengandalkan sosial media marketing yaitu perusahaan Startup. Namun, beberapa pengusaha termasuk pengusaha startup belum dapat memaksimalkan strategi digital marketing melalui media sosial. Menurut Park dan Kim, 
2003 (dalam Supriyono, 2020) beberapa pengusaha belum mengenal dengan baik digital marketing. Hal ini dikarenakan adanya beberapa anggapan bahwa strategi digital marketing memiliki kesamaan dengan strategi pemasaran secara umum. Padahal jika ditelaah lebih lanjut, ada banyak aspek yang perlu diperhitungkan di dalam menjalankan strategi digital marketing, salah satunya kualitas informasi. Kualitas informasi terdiri dari kualitas informasi produk, informasi situs dan informasi layanan. Jika informasi yang disajikan tidak memenuhi syarat atau tidak lengkap, maka upaya promosi dengan sosial media marketing akan sia-sia. Padahal bagi perusahaan startup terutama yang belum terlalu dikenal oleh masyarakat, akan sangat bagus jika memaksimalkan sosial media karena dapat memperkenalkan dan mempromosikan semua bisnisnya juga kelebihan yang dimiliki untuk menarik para konsumen.

Social media marketing selain berkaitan dengan kegiatan pembelian dan penjualan atau brand awareness, juga membuat para pelaku usaha harus mampu menciptakan komunikasi yang baik dengan pelanggan (konsumen) sehingga mereka merasa nyaman. Karena melalui media sosial, diharapkan para pelaku usaha dapat berinteraksi dengan konsumen, memberi jawaban atas pertanyaan dan keluhan, mengumumkan produk dan layanan baru, memperoleh umpan balik dan rekomendasi, serta membangun komunitas. Dengan cara ini, konsumen dapat mulai membangun kepercayaan terhadap perusahaan (Supriyono, 2020). Karena saat ini, para konsumen terutama konsumen produk dari bisnis startup selalu ingin mengetahui pendapat konsumen lain supaya dapat membuat pertimbangan ataupun perbandingan. Misalnya sebelum memutuskan untuk membeli sebuah produk, mereka akan terlebih dahulu membaca testimoni dari konsumen yang sudah pernah membeli dan mencoba produk tersebut apakah baik atau tidak. Sehingga mereka dapat merasa aman dan percaya untuk melakukan transaksi pembelian.

Untuk mem-branding produk diperlukan tujuan, yaitu keterikatan dengan para calon konsumen di media sosial. Dengan adanya bermacam bentuk keterikatan, maka akan menimbulkan terciptanya berbagai tindakan. Lalu jika untuk mendorong kesadaran merek, maka harus banyak menyajikan konten yang akan dilihat oleh publik (pengikut, pelanggan/konsumen) supaya dapat membantu menyebarluaskan produk sehingga ada banyak orang yang mengenal dan menyebarluaskan merek tersebut. Keterikatan dengan pelanggan / konsumen dapat meningkatkan kesadaran mengenai merek tersebut. Dengan demikian, pentingnya media sosoal sebagai alat yang dapat membantu meningkatkan koneksi secara pribadi yaitu dengan memulai memperoleh partisipasi dari bisnis dan konsumen.

Perusahaan startup dalam membuat konten di yang akan diposting di media sosial usaha tidak boleh asal-asalan, terlalu panjang, membosankan, bahkan tidak menarik sama sekali. Hal itu tentu membuat para pengguna media sosial malas untuk membaca postingan tersebut dan melewatkannya. Konten yang bagus yaitu yang memberikan nilai pada keterikatan konsumen. Karena jika konten media sosial usaha dapat memberikan nilai keterikatan konsumen, maka akan menarik banyak pengguna media sosial untuk menjelajahi media sosial usaha tersebut. Dengan demikian, konten yang dibuat harus benar-benar bermanfaat, menarik, mempengaruhi, memunculkan rasa penasaran, serta mempertimbangkan psikologi konten media sosial. Media sosial usaha tidak selalu harus memposting konten mengenai bisnis yang dimiliki dan mempromosikan produk / merek secara langsung, tetapi dapat juga dapat untuk menyebarkan konten yang bermanfaat.

Semua yang dibahas di atas sejalan dengan penelitian sebelumnya yang dilakukan oleh Josshte \& Kuvykaite yang mengemukakan bahwa media sosial telah mengubah komunikasi tradisional antara merek dan konsumen dan memungkinkan konsumen untuk membuat pengaruh positif dan negatif pada merek. Oleh karena itu, perusahaan harus dapat mengetahui bagaimana mengelola komunikasi media sosial yang baik sebagai usaha membangun merek. 


\section{KESIMPULAN}

Hasil dari analisis data di atas yaitu penggunaan media sosial sebagai alat untuk melakukan promosi bisnis sangat bagus jika dijadikan strategi pemasaran perusahaan startup Indonesia, karena banyak memiliki kelebihan dan keuntungan yang diperoleh. Dan akan lebih efektif jika disiapkan dengan strategi marketing yang tepat, yaitu dengan memperhatikan kualitas informasi yang terdiri dari kualitas informasi produk, informasi lokasi dan informasi layanan. Selain itu, strategi branding menggunakan media sosial melibatkan dua diantaranya adalah strategi komunikasi/konten dan strategi keterlibatan untuk strategi pengukuran untuk menyampaikan pesan konten agar dapat menjangkau konsumen. Namun, sangat penting untuk memproses branding media sosial sesuai dengan perannya sehingga dapat membentuk kesadaran merek.

\section{DAFTAR PUSTAKA}

Adhari, I. Z. (2020). Strategic policies \& business models for artificial intelligence-based digital printing startup in Indonesia. Management and Entrepreneurship: Trends of Development, 4(14), 78-101. https://doi.org/10.26661/2522-1566/2020-4/14-07

Basri, W. S., \& Siam, M. R. A. (2017). Maximizing the social media potential for small businesses and startups: A conceptual study. International Journal of Economic Perspectives, 11(2), 241-245.

Chen, Z. F., Ji, Y. G., \& Men, L. R. (2017). Strategic Use of Social Media for Stakeholder Engagement in Startup Companies in China. International Journal of Strategic Communication, 11(3), 244-267. https://doi.org/10.1080/1553118X.2017.1298114

Cohive.space. (2018). Apa Itu Startup? Apa Bedanya Dengan Online Shop / Bisnis Online?. Diakses pada 26 April 2021 dari www.Cohive.Space. https://cohive.space/blogs/apaitu-startup-apa-bedanya-dengan-online-shop-bisnis-online-cohive/

Graham, P. (2012). Startup. http://www.paulgraham.com/growth.html. Diakses pada 26 April 2021

Gumpo, C. I. V., Chuchu, T., Maziriri, E. T., \& Madinga, N. W. (2020). Examining the usage of Instagram as a source of information for young consumers when determining tourist destinations. SA Journal of Information Management, 22(1), 112. https://doi.org/10.4102/sajim.v22i1.1136

Hanifawati, T., Ritonga, U. S., \& Puspitasari, E. E. (2019). Managing Brands' Popularity on Facebook: Post Time, Content, and Brand Communication Strategies. Journal of Indonesian Economy and Business, 34(2), 185. https://doi.org/10.22146/jieb.45755

Kasuma, C. Y. S., Indrawati, R., \& Iswanto, A. H. (2019). Marketing Strategy for Start-Up: a Study of Home Care Business. Russian Journal of Agricultural and Socio-Economic Sciences, 91(7), 297-301. https://doi.org/10.18551/rjoas.2019-07.34

Startupranking.com. (2021). Start-up Ranking Countries. Diakses 20 April 2021, dari Startupranking.com: https://www.startupranking.com/countries

Wahyuwidagdo, P., \& Fachreza, I. (2018). Event Marketing: How Social Media Start-Up Seeties App Acquires Users In Indonesia Primadi Wahyuwidagdo; Iqbal Fachreza. $1(2), 1-11$. 